\title{
A CONCEPTUAL MODEL FOR ORGANIZATIONAL COMPETENCES
}

\author{
Hammouch, Hanane (1); \\ Hein, Andreas Makoto (1); \\ Condat, Helene (2)
}

1: Université Paris-Saclay, CentraleSupélec, Laboratoire Genie Industriel, 3 rue Joliot-Curie, Gif-surYvette, France;

2: Initiative for Interstellar Studies (i4is), 27/29 South Lambeth Road, London SW8 1SZ, UK

\begin{abstract}
Organizational competences are one of the main assets of companies. Models of these competences would allow for systematic reasoning for exploring technological innovations, enabled by combining and transposing organizational competences. Today, the literature linking organizational competencies to engineering design and systems engineering remains limited. In particular, a generic modelling approach for organizational competencies for engineering design and systems engineering seems to be missing, although first frameworks have been proposed for specific purposes. This paper presents a generic conceptual model of organizational competences. The objective is to link technology, product, and systems development with the corresponding organizational competencies and their future evolution in order to allow for a joint design of competencies and technologies, products, or systems. The conceptual model provides the basis for a competence combination framework which allows for modeling competence combinations in an organization. Finally, we validate our conceptual model using a case study from the automotive industry.
\end{abstract}

Keywords: Organizational processes, Systems Engineering (SE), Innovation, Technology

\section{Contact:}

Hein, Andreas Makoto

CentraleSupelec

France

andreas-makoto.hein@centralesupelec.fr

Cite this article: Hammouch, H., Hein, A. M., Condat, H. (2021) 'A Conceptual Model for Organizational Competences', in Proceedings of the International Conference on Engineering Design (ICED21), Gothenburg, Sweden, 16-20 August 2021. DOI:10.1017/pds.2021.5 


\section{INTRODUCTION}

Organizational competences are one of the main assets of large and complex companies (Christensen and Kaufman, 2006). They form the basis for technologies, systems, and products these companies can develop, produce, and operate etc. (Hein, 2016). Models of these competences would allow for a systematic reasoning on combining or acquiring them with the objective to explore which new technologies, systems, and products would be accessible to an organization (Hein et al., 2014). In the following, we consider models of organizational competences as one way of exploring technological innovations, which might ultimately lead to the design of new systems and products.

Numerous publications on organizational competences, also referred to as "capabilities", exist in the domain of management, specifically strategic management, technology management, and innovation management (Burgelman et al., 1996; Gerybadze, 1998; Prahalad and Hamel, 1990; Schilling, 2013). However, they usually remain at a descriptive level and few approaches for modelling organizational competences have been proposed, for example, Prahalad and Hamel (1990) as an exception. In particular, the link between organizational competences and technology / systems / product development has received limited attention (Hein et al., 2014). For example, Bonjour, E., \& Micaelli (2010) bridge strategic management and design management by proposing a framework for modelling design competences and establish a link to product, process, and organization. They use design structure matrices for representing these aspects and apply the approach to the automotive sector. Similarly, Danilovic and Leisner (2007) use design structure matrices for relating core competences of a company to its products, in order to identify core products. Hein (2016) proposes a competence model for the field of systems engineering, with the objective of assessing the reusability of technologies, i.e. for assessing the extent to which the underlying competences of a technology exist. Hein et al. (2014) propose a framework for modelling organizational competences in order to jointly architect organizational competences and system architectures. To conclude, a rich literature on organizational competences exists within the domain of management. However, the literature linking organizational competences to engineering design and systems engineering remains limited. In particular, a generic modelling approach for organizational competences for engineering design and systems engineering seems to be missing, although first frameworks have been proposed for specific purposes such as technology reuse and systems architecting.

To address this gap, this paper presents a generic conceptual model of organizational competences as a basis for modelling organizational competences. The end goal is to link technology, product, and systems development with the corresponding organizational competences. Linking these elements would enable, for example, to analyse how far the current competencies of an organization are sufficient for developing a technology or whether the required competencies can be acquired.

To develop the conceptual model, we conduct a literature survey on existing competence definitions and summarize their main characteristics as a first step. As a second step, we propose a competence definition, conceptual model, and a framework for combining competences. As a third step, we validate our conceptual model using a case study from the automotive industry.

\section{THE CONCEPT OF COMPETENCE}

Competence has become a focus of interest for many actors in various fields. In this section, we present the main definitions of competence in different fields, with the purpose of identifying components of a competence, which can be subsequently used in the conceptual model. For this purpose, we also surveyed the literature on competences of individuals, notably from the field of education, as more mature conceptual models of competences exist in this domain. In the following, we focus on the literature from the management domain, education sciences, and philosophy. Furthermore, we address some synonyms and summarize the main characteristics of these definitions that provide guidance for the subsequent conceptual model.

\subsection{Competence definitions}

The term competence is described in many ways. In technology management, Christensen et al. (2015) point out that organizational competences reflect what an organization can or cannot do. They shed light on three key factors "resource", "process", and "value". Other researchers consider competences as a key to competitive advantage. Schilling (2013) uses the term "ability" to describe competence as a 
"set of integrated and harmonized abilities that distinguish the firm in the marketplace". Prahalad and Hamel (1997) introduce the term "core competencies" to describe "the collective learning in the organization, especially how to coordinate diverse production skills and integrate multiple streams of technologies". Core competencies should, therefore, allow for competitive advantage by creating a valuable product or service for the company. They should be hard to imitate, rare, and have the potential to profit from it (e.g. for various products or various markets). Moreover, Gallon, Stillman, and Coates (1995) describe core competencies as "the things that some companies know how to do uniquely well and that have the scope to provide them with a better-than-average degree of success over the long term".

From an engineering design perspective, Bonjour and Micaëlli (2010) add that a core competence can be developed. Competences of design organizations such as those pertaining to departments, offices, suppliers and teams contribute to the development of corporate core competences. Some researchers link the concept of core competence to product design. As mentioned in the introduction, Bonjour and Micaëlli (2010), Danilovic and Leisner (2007), as well as Hein et al. (2014) propose matrices for mapping specific core competencies to a company's projects and core products. These matrices allow to identify clusters of core competence - projects / core products mappings that are strategically important. Based on this analysis, the company can subsequently allocate resources in a targeted fashion to develop existing and new core competences. However, the way and the logic in which the core competences are defined and decomposed are not defined.

To conclude, the existing management and engineering design literature consider competence mainly in the context of an organization's competitive advantage.

The education sciences look at competences of individuals. In the following, we are interested in the concepts that are linked to competences, which might be transferrable to organizational competences. Sampson and Fytros (2008) added the "context" dimension to competences. This dimension aims to refer to a specific area of a job, to a specific situation, to a work-related situation or to a specific task. The second dimension of his competence definition is "proficiency level", which aims to classify competences at a specific performance level for a given activity. The last dimension concerns "personal characteristics" that embody skill, knowledge and attitudes. Based on those three dimensions, El Asame and Wakrim (2018) describe competence as "a set of personal characteristics (skills, knowledge, attitudes, etc) that a person acquires or needs to acquire, in order to perform an activity inside a certain context with a specific performance level". Competences are described for defining and measuring required competences with regard to the intended learning objectives.

Drawing from the literature in philosophy, Hein (2016) adds that a competence "has a more or less defined "object" on which the competence acts upon" called an object of competence and an agent "which can perform an action". The competence can be either "a specific competence" or "a general competence". A general competence is a competence that does not depend on external circumstances to exist. This is the case for a competence that is present even if the process or technology enabling the deployment of the competence is absent. A specific competence, on the other hand, is one that is linked to specific external circumstances or factors in order to exist. Consequently, the assessment of the existence of this specific competence is made by evaluating whether these circumstances or external factors are present (Vetter, 2015, p.127).

Another term which is used to describe competence is "know-how". Durand (2015) defines know-how as a practice related to the ability to act in a concrete way according to a predefined process or objectives. Know-how does not preclude knowledge, but may not require a fundamental understanding of the reasons why empirical tricks and techniques work. Know-how is empirical and, at least in part, tacit. Garud (1997) observes that the term "know-how" is often used to express knowledge in general, although he goes on to distinguish between three different types of knowledge: know-why, know-how, and know-what. However, know-how is considered at least an important element, if not the underlying element of a competence. Transferred to organizational competence, a competent organization is an organization that has the knowledge to do something, i.e. the organization has the know-how that enables to organize activities such as executing actions and/or using resources (e.g. an organization has the know how to design a component which means that it knows how to execute an action related to a 3D model component using Solidworks).

We can conclude that philosophical definitions deal with general definitions in a broad sense which are relevant to address a general taxonomy and terminology of competence. Those definitions do not 
depend on the competence's purpose or domain. Thus, these general definitions provide a theoretical background for what a competence is.

Despite the interchangeability of the terms, there are also debates about the meaning of the terms "competency" and "competence". Sampson and Fytros (2008) point out that some authors use "competencies" to mention the plural of the term "competence" while others argued that "competency" complements competency as deployed in the UK occupational standards. Vazirani (2010) and Hoffmann (1999) argue that "competency" has been used as a "description of behavior" while "competence" has been used as a "description of work tasks or job output". For the sake of simplicity and for avoiding confusion between "competence" and "competency" terms, we will use both interchangeably in the following.

\subsection{Competence characteristics}

From the literature survey in Section 2.1, we extract the following points as the main characteristics of competence:

- Requires resources and preconditions either tangible or intangible.

- Is related to an agent, this agent can be an individual or organization.

- Can use tangible and intangible "resources".

- Can be assigned to a context in which it is applied.

- Is general in case the presence of specific external circumstances such as resources does not impact its existence or specific in case it is bound to specific external circumstances to exist.

- Definitions consist of the elements: knowledge, skill, ability, know-how. The main element that captures those elements and fits with competence is the know-how.

- Has a performance associated with it.

From these characteristics, we can conclude that three basics elements constitute a competence. We provide a schema (Figure 1) that encompasses those elements and the different meaning of competence based on the taxonomy listed in the subsection 2.1 it contains those notions:

- Agent of competence: to describe the entity that can perform a competence.

- Competence element: Refers to the main element of competence that we will take into consideration. According to our schema, this competence element can be used, possessed, developed, or acquired (Hein, 2016).

- Object of competence: Refers to the resulting thing (deliverable) and things used or operated (resources) to obtain the deliverable.

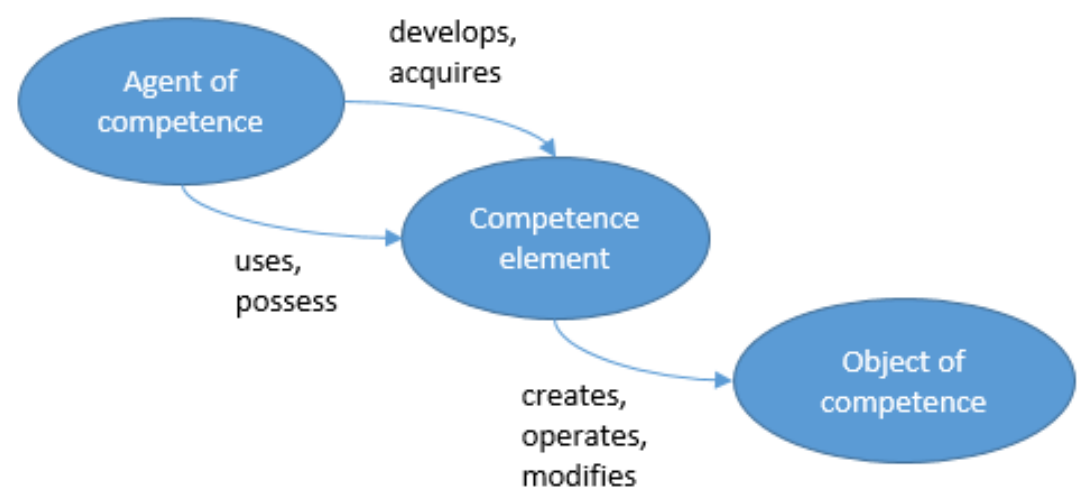

Figure 1. Competence basic elements

After defining the main competence characteristics, we further define a competence element as "knowhow". Thus, we can define organizational competence as: "A know-how that allows an agent of competence to perform an action on the object of competence in a defined competence area (and using resources)."

Moreover, some organizations will face strategic business decisions such as selecting subcontractors. The selection of subcontractors will be based on the identification of what they are able to do. Is it only having a competence to perform specific actions? Or also having the necessary resources? Thus, 
two types of competences can be explicitly distinguished from the definition depending on what having a competence means. In some contexts, for example, manufacturing, typically the resources enabling executing the competence should be present, in order to consider the competence to be existing. While in another context, a company can be considered as competent without requiring those necessary resources. Thus, to ensure covering those important distinctions we propose two additional competence definitions.

The former is a general competence described as "A know-how that allows an agent of competence to perform an action on the object of competence in a defined competence area". The latter is a specific competence described as "A know-how that allows an agent of competence to perform an action on the object of competence in a defined competence area and using resources."

\section{A CONCEPTUAL MODEL FOR ORGANIZATIONAL COMPETENCIES}

In this section, we will propose our conceptual model for organizational competence in accordance with the competence characteristics and our previous competence definitions. This model intends to support organizations to define their actual competences, combining and transposing them to jointly design technologies, products, or systems. We provide a case study as a validation approach of our conceptual model.

\subsection{Basic concepts and competence vs. function}

Based on the previously discussed literature, we distinguish between "general" and "specific" competence. We also conclude that "resources" and "actions" are needed for the description of competence. More precisely, "actions" are required for a general competence while in addition, "resources" are necessary for the execution and the existence of a specific competence. A specific competence is considered, therefore, as a general competence applied in a specific context and which requires specific resources to exist. Thus, a specific competence is a specific case of a general competence. For example, a company that has an organizational competence of producing cars has a general competence of producing cars while it has the theoretical know-how or an understanding about how to organize activities required to execute actions such as developing prototypes, developing mules, mastering planning, managing production, and assemble workflows without considering if it has the production line, assembly line, and equipment at its disposal at all moments. By contrast, a company has the specific competence to produce cars if it can use the general competence within a specific context, which requires the existence of the previously mentioned resources, i.e. concretely producing cars. This means that the company can execute actions (e.g. managing production workflow), using resources (e.g. production and assembly lines and equipment) to produce cars.

Moreover, a "resource" is an input of an "action" and the "deliverable" is the output of an "action". For example, the production / assembly site, and modelling software are inputs for the action of 3D modelling that enables to produce prototypes as deliverables. This synergy of thinking about actions and their in- and outputs corresponds to the elements of a function model. A common interpretation of a function is that it transforms inputs into outputs (Otto, et al., 2001 and McInnes, et al., 2010). Here, the "action" can be interpreted as "function", the "resource" as the "input" and "deliverable" as the "output" of the function. For simplifying the model, "input" and "output" can be represented as roles of an "object", shown in Figure 2. This link to function models is useful for linking competence models to process models, as will be illustrated in more detail in the case study.

From the perspective of our conceptual model, a function can be interpreted as the "actions" associated with a competence, the input of the function as the "resources" operated or used and necessary for the specific competence, the output of the function as the "deliverable" resulting from the competence, and the object as the "object of competence". Moreover, our competence model will indicate how to distinguish between functional and competence models and enables to clearly define the link between the competence domain and functional domain in a way that our competence model can be interfaced with existing functional models in the organization such as BPMN (White, 2004). 


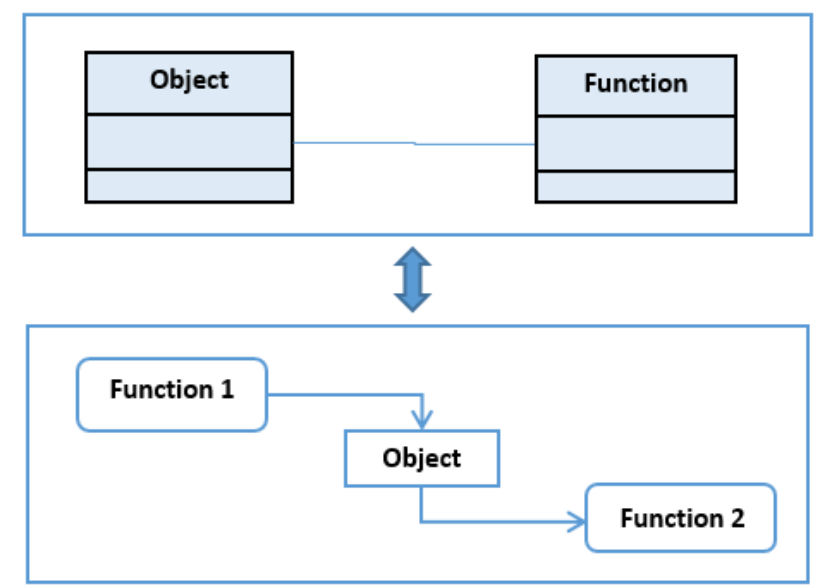

Figure 2. Basic functional model elements

\subsection{Conceptual model}

From the concepts introduced before, we define key concepts of an organizational competence model:

- $\quad$ Agent of competence: Is the agent who uses, possesses, acquires or develops the competence.

- Competence area: Is the context in which competence elements are carried in term of domain or life cycle phase of the deliverable.

- General competence: This element refers to the know-how about something required to execute actions.

- Specific competence: Refers to the know-how about something required to execute actions and requires resources.

- Action: An Action that can be executed since the general competence is used, possessed, acquired, or developed by the agent of competence.

- $\quad$ Resource: Refers to the necessary resources required for using the know-how.

- Object of competence: Refers to the object which is subject of the competence. It can be assigned two roles: "resource" or "deliverable".

Our organizational competence model in Figure 3 is also defined by its constituent elements and their interactions and characteristics: The "agent of competence" can be an individual (e.g. collaborator), a collective (e.g. department, service or organization....etc.), internal to the company (i.e. an agent that is able to use the existing competence or to acquire a new competence), outside of the company (i.e. if a decision is made to collaborate with the agent of competence). The "competence area" allows to specify the competence context in terms of the organizational competence domain. For example, an organizational competence may concern the automotive domain or aeronautical domain. This element also allows to ascribe a life cycle phase to the deliverable of the competence. For example, an automotive department may possess a competence pertaining to the design, development, production, assembly, and/or operations life cycle phase.

Our conceptual model allows to aggregate several general competences. This is expressed by the composition link between competence area and general competence. General competence is the general know-how required to execute "action" and it is defined as the generalization of specific competence which is defined by the inheritance link between them. In addition, specific competence necessitates "resources" for the existence of the specific competence which are represented as an "object of competence" acting in its role as "resource". A general competence consists also of developing, creating, operating or modifying the "deliverable" which is represented in the functional model domain as the "output "of the function or an "object" playing the role of "deliverable". Specific competence necessitates "resources" for the existence of the specific competence. As we concluded previously, to make the link with functional model domain, the resources can be presented as the "input" of the function or as an "object of competence" acting in its role as "resource". The general competence consists of developing, creating, operating or modifying the "deliverable" which is represented in the functional model domain as the "output" or an "object" playing the role of the 
"deliverable". An object of competence can be an aggregation of an arbitrary number of objects of competence, indicated by the composition relationship (black diamond). Resources can be aggregations of resources and deliverables can be aggregations of deliverables. The yellow square indicates the boundaries of the elements of the conceptual model used in the case study in Section 4.

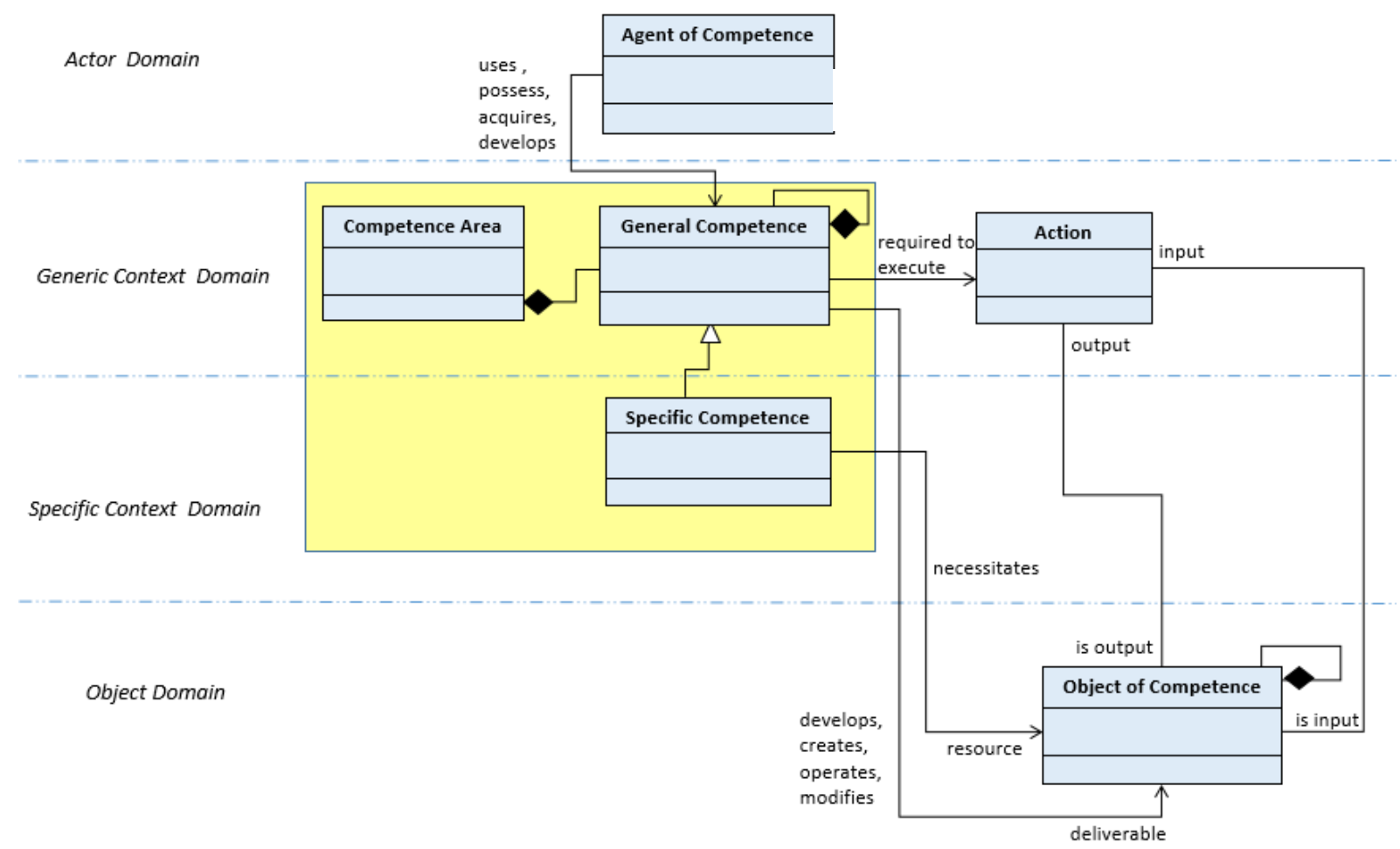

Figure 3. Organizational competence conceptual model

The elements of the proposed model allow to represent both generic and specific competences depending on the context of use of the competence. The model aims to provide a description at a high level of abstraction in terms of the domains covered, actions executed, resources used, and deliverables generated.

\subsection{Competence combination framework}

The conceptual model provides the basic elements for representing the combination of organizational competences. In addition, we present a specific framework, shown in Figure 4 which allows to represent the combination of competences.

We identify two main mechanisms for combining competences: Interrelation and integration. The former consists of identifying connected or shared competence elements for both competences within the same life cycle phase. For example, a car manufacturer can combine competences within the car design phase. The combination will consist of taking into account the connected or shared actions (e.g. coordinated activities that should be taking into account for combined competences: updated requirements for designing the heating, ventilation, and air conditioning (HVAC) components of a car can impact the design of the power consumption components) and resources (e.g. a shared production meeting that requires the participation of car component designer should be mentioned) within the production life cycle of a car.

Integrating competences consists of identifying the connected or shared competence elements for competences in different life cycle phases. For example, a car manufacturer can combine competences within the car design, development, verification, validation and production phase. The combination will consist of combining general and specific competences by taking into account the connected or shared actions and resources that ensure competence integration such as backward and forward traceability (e.g. documents enabling the traceability and justification of requirements). 
The competence combination framework also allows for modelling competences at different levels of granularity. We can, for example, choose a low granularity by modelling the combination of competences as a single competence. Recursively, a higher granularity model can be developed via representing the interrelation and integrated elements at lower hierarchical levels.

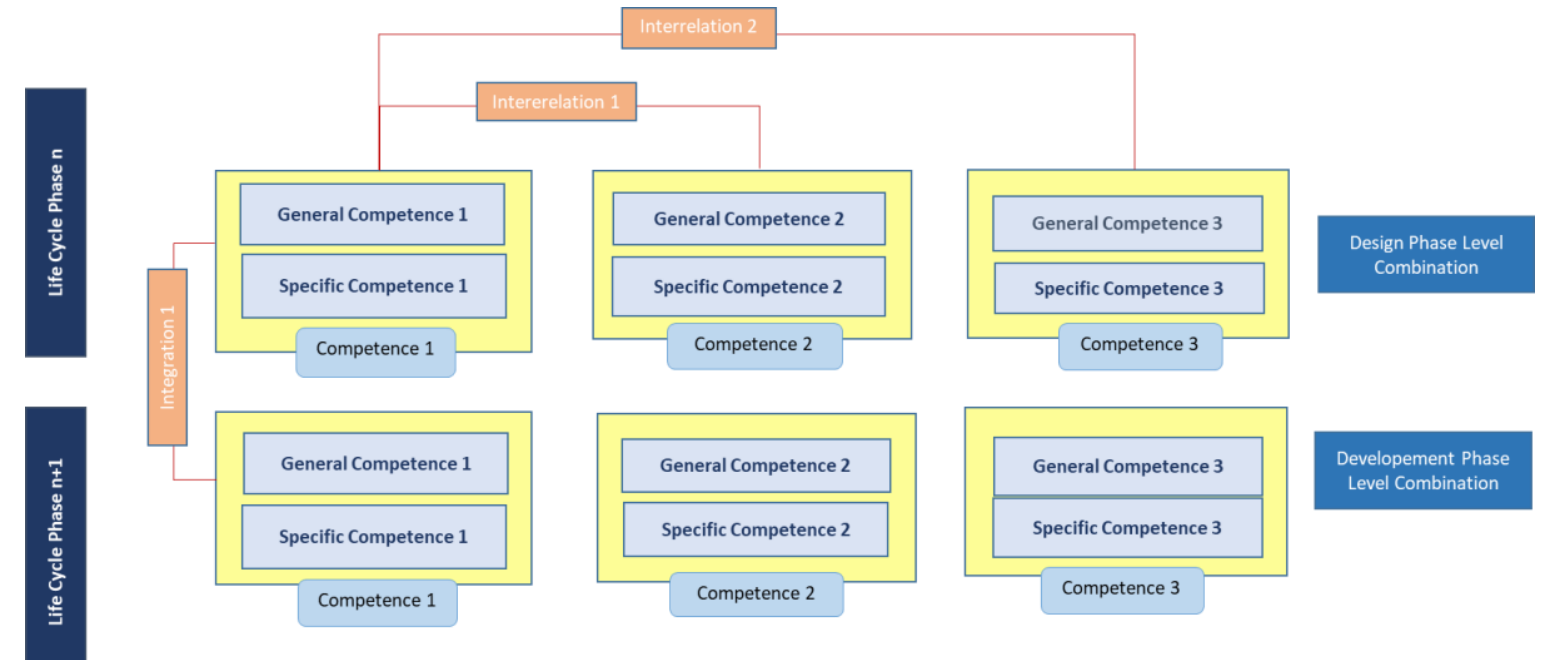

Figure 4. Competence combination framework

We believe that our conceptual competence model contains the main elements and characteristics enabling the representation of organizational competences. Due to its generic nature, we expect it to be applicable to diverse organizational contexts.

\section{CASE STUDY}

We provide an example of applying the organizational competence model to a case study from the automotive domain. The case study was selected as a validation approach of our conceptual model. For this end, we apply the model to a case study from the automotive sector. We selected this case study to demonstrate that our modelling approach can be applied to an industrial company and a domain that involves developing complex products.

The case study is related to the competence of designing an automotive feature. A small subset of a much larger model is shown in Figure 5. The content of the model shown here has been anonymized and is limited to publicly available data.

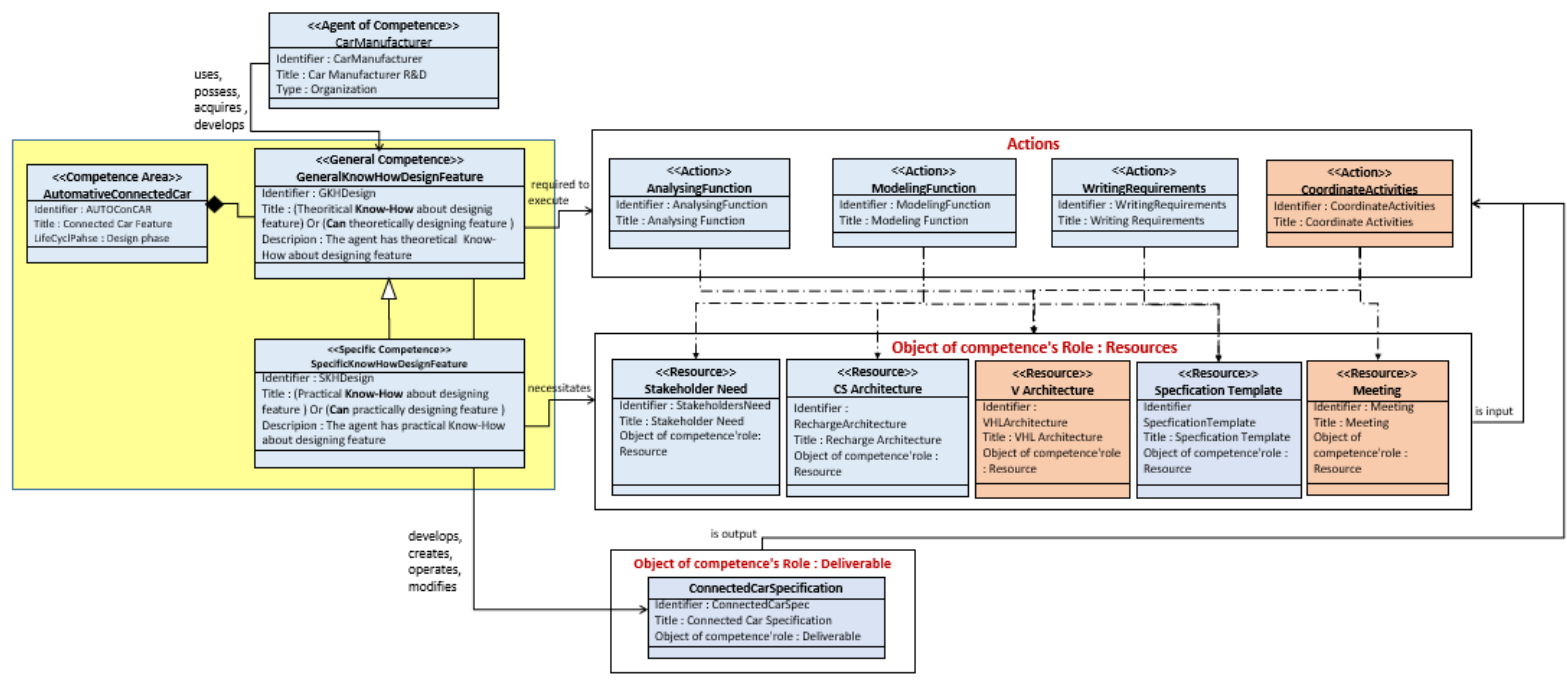

Figure 5. Example of organizational competence 
It can be seen that the competence model includes the competence elements, represented via Systems Modeling Language (SysML) stereotypes. SysML stereotypes are expressed via double brackets $\langle<\ldots\rangle\rangle$. Figure 5 shows the competence area (automotive domain, connected car, life-cycle phase: design phase), agent of competence (car manufacturer), inputs of actions i.e. resources (e.g. stakeholder needs, connected car architecture, design meetings, specification template etc.) required to execute actions (e.g. modelling function). The actions and resources can be linked to a function or process model of the organization, for example, a business process model. For example, the modelling function action could be linked to a modelling function business process. Thereby, the competence of designing a connected car feature could be linked to a business process model for designing a connected car feature. This enables companies to make a clear distinction between competences and processes. The deliverable (connected car specification) is the output of the competence.

Via this case study, we demonstrated that our conceptual competence model can, in principle, be applied to an industrial context of developing a complex product. The next step is to validate our conceptual model in a real project context as well as in different domains.

\section{CONCLUSION AND FUTURE WORK}

In this paper, we proposed a conceptual model for organizational competences, including constituting elements of an organizational competence and their relationships. The conceptual model provides the basis for modelling competence combinations within an organization via a competence combination framework. As a result, the model could be used as a framework to combining competences to explore which technologies, products, or systems can be developed by an organization. We validate our conceptual model using a case study from the automotive industry. Concerning future research, we will investigate the value of this conceptual model in industry in an actual project.

\section{REFERENCES}

Bonjour, Éric, and Jean Pierre Micaëlli. 2010. "Design Core Competence Diagnosis: A Case from the Automotive Industry." IEEE Transactions on Engineering Management 57(2): 323-37.

Burgelman, R.A., Maidique, M.A., Wheelwright, S.C., 1996. Strategic Management of Technology and Innovation, 2nd ed. ed. McGraw-Hill Education.

Christensen, C., Kaufman, S., 2006. Assessing your organization's capabilities: Resources, processes and priorities. Harvard Bus. Sch. Modul. Note 607-014.

Christensen, C. M., Raynor, M. E., \& McDonald, R. (2015). What is disruptive innovation. Harvard business review, 93(12), 44-53.

Danilovic, M., \& Leisner, P. (2007). Analyzing core competence and core products for developing agile and adaptable corporation. In DSM 2007: Proceedings of the 9th International DSM Conference, Munich, Germany, 16.-18.10. 2007 (pp. 49-60).

Durand, T. (2015). L'alchimie de la compétence. Revue française de gestion, 41(253), 267-295.

El Asame, M., \& Wakrim, M. (2018). Towards a competency model: A review of the literature and the competency standards. Education and Information Technologies, 23(1), 225-236.

Maier, J., 2014. Abilities [WWW Document]. The Stanford Encyclopedia of Philosophy. URL http://plato.stanford.edu/archives/fall2014/entries/abilities/ (accessed 5.14.15).

McInnes, A. I., Eames, B. K., \& Grover, R. (2010). Formalizing functional flow block diagrams using process algebra and metamodels. IEEE Transactions on Systems, Man, and Cybernetics-Part A: Systems and Humans, 41(1), 34-49.

Merriam-Webster Inc., 2004. Merriam-Webster's collegiate dictionary. Merriam-Webster.

Gallon, M. R., Stillman, H. M., \& Coates, D. (1995). Putting core competency thinking into practice. ResearchTechnology Management, 38(3), 20-28.

Garud, R. (1997). On the distinction between know-how, know-what, and know-why. Advances in strategic management, 14, 81-102.

Gerybadze, A., 1998. Technological competence assessment within the firm: applications of competence theory to managerial practice, Discussion Paper on International Management and Innovation, 98-03. Universität Hohenheim, Stuttgart.

Hein, A. M. (2016). Heritage technologies in space programs-assessment methodology and statistical analysis (Doctoral dissertation, Technische Universität München).

Hein, A.M., Metsker, Y., Sturm, J.C., 2014. Towards a capability framework for systems architecting and technology strategy, in: 16th International Dependency and Structure Modelling Conference, DSM 2014. 
Hoffmann, T. (1999). The meanings of competency. Journal of European Industrial Training.

Otto, K., \& Wood, K. Product Design: Techniques in Reverse Engineering, Systematic Design, and New Product Development. 2001.

Prahalad, C. K., \& Hamel, G. (1997). The core competence of the corporation. In D. Hahn \& B. Taylor (Eds.), Strategische Unternehmungsplanung / Strategische Unternehmungsführung: Stand und Entwicklungstendenzen (pp. 969-987). Heidelberg: Physica-Verlag HD. https://doi.org/10.1007/978-3-662-41482-8_46

Ritter T. The networking company: antecedents for coping with relationships and networks effectively. Ind Mark Manage 1999;28(5):467 - 79.

Ritter, T., \& Gemünden, H. G. (2003). Network competence: Its impact on innovation success and its antecedents. Journal of business research, 56(9), 745-755.

Schilling, M., 2013. Strategic management of technological innovation, 4th Editio. ed. McGraw-Hill.

Sampson, D., \& Fytros, D. (2008). Competence models in technology-enhanced competence-based learning. In H. H. Adelsberger, Kinshuk, J. M. Pawlowski, \& D. Sampson (Eds.), Handbook on information.

Vazirani, N. (2010). Review paper: Competencies and competency model-A brief overview of its development and application. SIES Journal of management, 7(1), 121-131.

Vetter, B., 2015. Potentiality: From Dispositions to Modality. Oxford University Press.

White, S. A. (2004). Introduction to BPMN. Ibm Cooperation, 2(0), 0. 